\title{
A Highly Specific Probe for Sensing Hydrogen Sulfide in Live Cells Based on Copper-Initiated Fluorogen with Aggregation-Induced Emission Characteristics
}

\author{
Xin $\mathrm{Li}^{1}$, Chengyu Yang${ }^{2}$, Kai $\mathrm{Wu}^{2}$, Yongzhou Hu${ }^{1}$, Yifeng Han ${ }^{2}$ and Steven H. Liang ${ }^{3} \bowtie$ \\ 1. ZJU-ENS Joint Laboratory of Medicinal Chemistry, College of Pharmaceutical Sciences, Zhejiang University, Hangzhou 310058, China \\ 2. The Key Laboratory of Advanced Textile Materials and Manufacturing Technology, Department of Chemistry, Zhejiang Sci-Tech Uni- \\ versity, Hangzhou, 310018, China. \\ 3. Division of Nuclear Medicine and Molecular Imaging, Massachusetts General Hospital and Department of Radiology, Harvard Medical \\ School, 55 Fruit St., Boston, MA 02114, USA.
}

\begin{abstract}
$\triangle$ Corresponding authors: Y. Han. Tel: 86571 86843550, Email: hanyf@zstu.edu.cn; S.H. Liang Tel: $6177263404, \quad$ Email: Liang.Steven@mgh.harvard.edu
\end{abstract}

() Ivyspring International Publisher. This is an open-access article distributed under the terms of the Creative Commons License (http://creativecommons.org/ licenses/by-nc-nd/3.0/). Reproduction is permitted for personal, noncommercial use, provided that the article is in whole, unmodified, and properly cited.

Received: 2014.08.13; Accepted: 2014.09.0I; Published: 2014.09.24

\begin{abstract}
Here we reported the first fluorescent probe with aggregation-induced emission characteristics, namely AIE-S, for the detection of hydrogen sulfide $\left(\mathrm{H}_{2} \mathrm{~S}\right)$ in live cells. The detection system is selective for complicated biological application and the response is fast enough to complete within seconds. Moreover, the probe exhibits the unique advantage of being immune to aggregation-caused quenching which is a detrimental phenomenon limiting the application of most current available $\mathrm{H}_{2} \mathrm{~S}$ fluorescent probes. The detection mechanism was investigated and postulated to be $\mathrm{S}^{2-}$ initiated de-coordination and thereafter aggregation of the AIE-S complex.
\end{abstract}

Key words: hydrogen sulfide, fluorescent probe, cell imaging, aggregation-induced emission

\section{Introduction}

Hydrogen sulfide $\left(\mathrm{H}_{2} \mathrm{~S}\right)$, notorious for the stink of rotten-eggs, was considered merely as a toxin with no beneficial physiological significance until the initial observations by Kimura's group suggesting its biological relevance as a signaling molecule. ${ }^{1}$ Ever since then, many research efforts have been made to unveil its biological roles, which established soundly $\mathrm{H}_{2} \mathrm{~S}$ as the third gasotransmitter after nitric oxide and carbon monoxide for its fundamental roles in human biology including its regulation and protection effects in the central nervous system, in the cardiovascular system, and in the inflammation process, etc. ${ }^{2,3} \mathrm{Hy}-$ drogen sulfide $\left(\mathrm{pK}_{\mathrm{a} 1} 6.755\right.$ at $\left.37^{\circ} \mathrm{C}\right)$ is produced in mammals from cysteine in a series of reactions mainly catalyzed by cystathionine $\beta$-synthase (CBS) and cystathionine $\gamma$-lyase (CSE). ${ }^{4,5}$ Endogenous $\mathrm{H}_{2} \mathrm{~S}$ is maintained at levels sufficient to modify cell function yet without causing poisonous effects in healthy conditions. 4,5 However, abnormal $\mathrm{H}_{2} \mathrm{~S}$ regulation has been associated with an array of diseases including hypertension, ${ }^{6}$ Alzheimer's disease, ${ }^{7}$ Down's syndrome ${ }^{8}$ and diabetes. ${ }^{9} \mathrm{H}_{2} \mathrm{~S}$ donors, on the other hand, have been reported to exhibit antihypertensive activity, ${ }^{10}$ antiproliferative effects, ${ }^{11}$ and neuromodulatory activity. ${ }^{12}$

Despite all the potential therapeutic implications, ${ }^{13}$ our understanding of the biological and pathological roles of this intriguing gas is still in its infancy. However, for any study of its biological functions, it is important to take the concentration at the site of action into first consideration. As such, it is crucial to have in place robust assays to monitor the 
biosynthesis, transport and catabolism of $\mathrm{H}_{2} \mathrm{~S}$ in living cells, tissues, as well as whole organisms. Traditional methods for $\mathrm{H}_{2} \mathrm{~S}$ detection, including the methylene blue assay. ${ }^{14}$ sulfide-selective electrodes ${ }^{6}$ and gas chromatography ${ }^{15}$ are generally limited by their invasive and destructive nature to live organisms. On the other hand, small fluorescent probes confer the advantages of high sensitivity and good cell permeability, and have therefore attracted the most attention for sensing and visualizing analytes inside living cells. A number of probes have been recently developed for the fluorescence detection of $\mathrm{H}_{2} \mathrm{~S}$ in biological systems. These probes, judiciously designed by taking advantage of nucleophilic, reductive properties of $\mathrm{H}_{2} \mathrm{~S}$ or its high binding affinity towards copper, can react specifically with sulfides with a fluorescence output signal indicating the presence or even concentration of $\mathrm{H}_{2} \mathrm{~S}$ in biological systems. ${ }^{16-27}$ However, previous $\mathrm{H}_{2} \mathrm{~S}$ probes are based on traditional planar aromatic chromophores which are only fluorescent in dilute solutions since high concentrations usually induce aggregation-caused quenching (ACQ) effect resulting from the strong $\Pi \Pi$ stacking interactions upon the aggregation formation. ${ }^{28}$ ACQ is generally considered harmful to practical applications because of the significant detection errors incurred. Unfortunately, traditional discotic fluorophores are usually highly hydrophobic and therefore easily aggregate in the aqueous biological contents. Although their hydrophilicity can be improved by the attachment of water-soluble functional groups, the resultant products are still vulnerable to ACQ in aqueous media due to the unalterable hydrophobicity. ${ }^{28}$ Novel probes with unique luminogen mechanism suitable for the specific detection of $\mathrm{H}_{2} \mathrm{~S}$ in high aqueous contents are thus still highly desirable.

Aggregation-induced emission (AIE), first reported in 2001, is a unique phenomenon that propeller-shaped fluorophores are non-emissive when molecularly dissolved but are highly fluorescent upon aggregation. ${ }^{29}$ It is proposed that these molecules cannot pack through а п п stacking process due to the propeller shape in the aggregate state, which restricts the intramolecular rotation, blocks the non-radiative pathway and opens up the radiative channel, leading to aggregation-induced emission. ${ }^{28}$ AIE is particularly attractive for biological aqueous environment and have showed diverse applications in cell imaging and bioprobes. ${ }^{30-33}$ However, AIE-based $\mathrm{H}_{2} \mathrm{~S}$-targeting probes are still unavailable. Here in this work, we disclose our related research efforts which resulted in the first probe with AIE characteristics for the sensing of biological $\mathrm{H}_{2} \mathrm{~S}$. The probe, namely AIE-S, demonstrated high specificity and sensitivity. Its feasibility to monitor $\mathrm{H}_{2} \mathrm{~S}$ in live cells was also confirmed.

\section{Experimental section}

\section{Materials}

Dry ethanol was distilled from sodium prior to use. Water was purified by a Millipore filtration system. Other chemicals and reagents were from commercial supplies and used without further purification. Reactions were monitored by thin-layer chromatography (TLC) carried out on Silica gel 60 F254 plates supplied by Qingdao Puke Separation Material Corporation using UV light as the visualizing agent. Flash column chromatography was performed using 200-300 mesh silica gel supplied by Qingdao Marine Chemical Factory, Qingdao, China.

\section{Instruments}

${ }^{1} \mathrm{H}$ and ${ }^{13} \mathrm{C}$ NMR spectra were recorded on a Bruker Fourier transform 400 NMR spectrometer at $25^{\circ} \mathrm{C}$ using $\mathrm{CDCl}_{3}$ as solvent and were calibrated referencing residual undeuterated solvent as an internal reference $\left({ }^{1} \mathrm{H} \mathrm{NMR}=7.26,{ }^{13} \mathrm{C} \mathrm{NMR}=77.16\right)$. All chemical shifts were given in ppm and coupling constants $(J)$ in Hz. The following abbreviations or combinations thereof were used to explain the multiplicities: $\mathrm{s}=$ singlet, $\mathrm{t}=$ triplet, $\mathrm{m}=$ multiplet. IR spectra were recorded on a Bruker Vector 22 spectrophotometer as $\mathrm{KBr}$ pellets. High resolution mass spectra (HRMS) were recorded on an Agilent 6224 TOF LC/MS spectrometer using ESI-TOF (electrospray ionization-time of flight). Absorption spectra were acquired using a Hitachi U-3010 spectrophotometer. Fluorescence measurements were carried out on a Perkin-Elmer LS 45 fluorescence spectrometer. Dynamic light scattering (Beckman-Coulter DelsaTM Nano-C particle analyzer) was used to determine the size of the aggregated particle colloids in aqueous solution.

\section{Synthesis of AIE-S}

To a stirred solution of tetraphenylethene aniline ( $200 \mathrm{mg}, 0.576 \mathrm{mmol}$ ) in dry ethanol was added salicylaldehyde $(3.00 \mathrm{~mL}, 28.7 \mathrm{mmol})$. The reaction was allowed going at ambient temperature under $\mathrm{N}_{2}$ atmosphere for $1 \mathrm{~h}$. A yellow precipitate was formed gradually which was isolated by filtration and further purified by flash column chromatography on silica gel (petroleum ether $/ \mathrm{CH}_{2} \mathrm{Cl}_{2}, 5: 1$ ) to afford AIE-S as a yellow powder $(234 \mathrm{mg}, 90 \%$ yield $) . \mathrm{Rf}=0.45(10: 1$ petroleum ether: EtOAc). ${ }^{1} \mathrm{H}$ NMR $\left(400 \mathrm{MHz}, \mathrm{CDCl}_{3}\right)$, $\delta$ (ppm): $13.30(1 \mathrm{H}, \mathrm{s}), 8.59(1 \mathrm{H}, \mathrm{s}), 7.37(2 \mathrm{H}, \mathrm{t}, \mathrm{J} 7.0)$, 7.15-7.01 $(20 \mathrm{H}, \mathrm{m}), 6.93\left(1 \mathrm{H}, \mathrm{t}, \mathrm{J}\right.$ 7.4). ${ }^{13} \mathrm{C}$ NMR $(100$ $\left.\mathrm{MHz}, \mathrm{CDCl}_{3}\right), \delta$ (ppm): 162.07, 161.29, 146.43, 143.75, $143.72,143.67,142.87,141.54,140.29,133.16,132.57$, $132.30,131.50,131.47,131.45,127.98,127.90,127.80$, $126.76,126.73,126.66,120.68,119.38,119.15,117.36$. IR 
$\left(\mathrm{cm}^{-1}\right): 3420,3025,1618,1567,1493,1450,1279,1181$, 753, 696. HRMS (ESI-TOF): $m / z 452.2018[\mathrm{M}+\mathrm{H}]^{+}$, calc'd. 452.2014 .

\section{Fluorometric analysis}

$N$-(2-hydroxyethyl)piperazine- $N$ '-2-ethanesulfo nic acid buffer (HEPES, $10 \mathrm{mmol}$, pH 7.4) was prepared with purified water and purged with nitrogen for 5 minutes before use. AIE-S was dissolved in THF to make a $200 \mu \mathrm{M}$ stock solution, which was diluted to $20 \mu \mathrm{M}$ with HEPES for measurements. $\mathrm{CuCl}_{2}$ and $\mathrm{Na}_{2} \mathrm{~S}$ were dissolved in the deoxygenated HEPES to make a stock solution of $1.0 \mathrm{mM}$. The spectrometer slit width of excitation and emission was adjusted to 5 and $10 \mathrm{~nm}$, respectively, for measurements. All fluorometric experiments were performed at room temperature in triplicate.

\section{Cell imaging}

HeLa cells were cultured in DMEM supplemented with $10 \%$ fetal bovine serum in a humidified atmosphere of $5 \% \mathrm{CO}_{2}$ at $37^{\circ} \mathrm{C}$. For imaging experiments, exponentially growing cells (at a density of 20000-40000 cells per well, respectively) were seeded in 24-well plate. Cells were cultured at $37^{\circ} \mathrm{C}$ in a $5 \%$ $\mathrm{CO}_{2}$ atmosphere for $24 \mathrm{~h}$ before they were exposed to reagents. After the staining steps as described in figure captions, the images were collected upon excitation using the corresponding filters for DAPI (blue).

\section{Results and discussion}

AIE-S was designed by fusing a $\mathrm{Cu}^{2+}$ chelating salen group which functions as a water solubility-adjusting group, to tetraphenylethene, a typical AIE fluorogen. ${ }^{28}$ The philosophy of our design is as follow. Existing as aggregates, AIE-S in aqueous solution would be highly fluorescent, while treating AIE-S with $\mathrm{Cu}^{2+}$ would lead to fluorescent quenching due to the improved water solubility of the AIE-S-Cu ${ }^{2+}$ complex. However, ascribed to the high binding affinity between $\mathrm{S}^{2-}$ and $\mathrm{Cu}^{2+}, \mathrm{Cu}^{2+}$ would be de-coordinated from the complex in the presence of $\mathrm{S}^{2-}$ to release the less miscible AIE-S and therefore trigger the restoration of the luminescent property of the system due to the increased local concentration and thereof the aggregation of AIE-S (Fig. 1).

The synthesis of AIE-S was straightforward via the reaction between salicylaldehyde and tetraphenylethene aniline with the latter being prepared according to reported procedures. ${ }^{34}$ It was obtained as a yellow powder in a yield of $90 \%$ and characterized by NMR and high-resolution mass spectroscopy.

With AIE-S in hand, we first investigated its photoluminescent property. AIE-S is soluble and thus non-emissive in tetrahydrofuran (THF). Its solubility decreased gradually as the volume fraction of HEPES buffer $(10 \mathrm{mM}, \mathrm{pH}=7.4)$ increased. The system reached its threshold when the buffer fraction increased to $70 \%$. In the THF-HEPES $(3: 7, \mathrm{v} / \mathrm{v})$ mixture, AIE-S was still weakly fluorescent even though the system showed an average particle size diameter of $214.0 \mathrm{~nm}$. When the buffer fraction was greater than $70 \%$, the system exhibited obvious emission peaked at $533 \mathrm{~nm}$ which intensified as the buffer fraction increased (Supplementary Material: Fig. S1). These results indicated that AIE-S was a typical fluorogen with aggregation-induced emission characteristics.

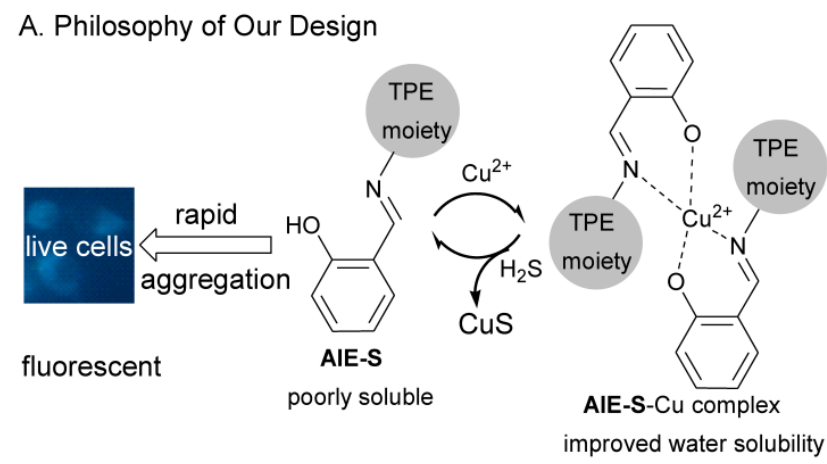

B. Synthesis of AIE-S

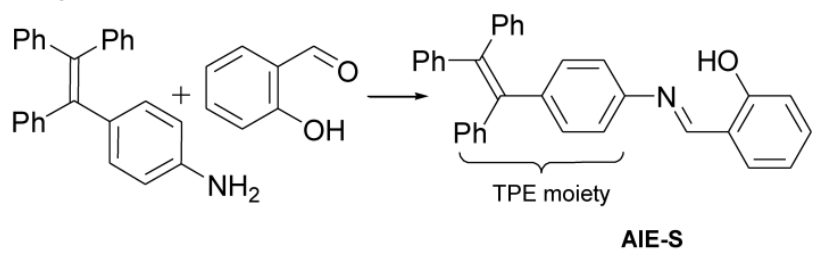

Fig. I. The philosophy of our design and the synthesis of AIE-S.

Next, the fluorescent responses of AIE-S towards various concentrations of $\mathrm{Cu}^{2+}$ were studied. Experiments were carried out in HEPES buffer (10 $\left.\mathrm{mM}, \mathrm{pH}=7.4,25^{\circ} \mathrm{C}, 10 \% \mathrm{THF}\right)$. As shown in Fig. 2, the blank solution of AIE-S ( $20 \mu \mathrm{M}$ in the buffer) exhibited intense fluorescence peaked at $533 \mathrm{~nm}$, while the addition of increasing concentrations of $\mathrm{Cu}^{2+}$ gradually attenuated the fluorescent signal and 95\% quenching was observed when 0.5 equiv. $\mathrm{Cu}^{2+}$ was added. The coordination between $\mathrm{Cu}^{2+}$ and AIE-S was confirmed by UV-Vis absorption spectra analysis (Supplementary Material: Fig. S2). AIE-S showed an absorption band stretching from 320-470 $\mathrm{nm}$ with the maximum peak centered at $375 \mathrm{~nm}$ assigned to the lowest-lying $\Pi-\Pi^{*}$ transition. Treatment of AIE-S with $\mathrm{Cu}^{2+}$ shifted the absorption with two peaks at 330 and $400 \mathrm{~nm}$, indicating the coordination of AIE-S with $\mathrm{Cu}^{2+}$. The stoichiometry of the complex was also determined to be 2:1 by a Job Plot indicating two AIE-S molecules bind to one $\mathrm{Cu}^{2+}$ ion (Fig. 3). 


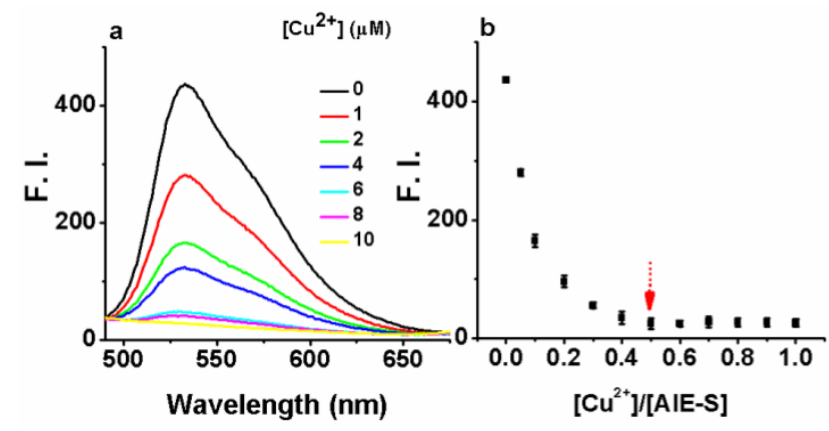

Fig. 2. The turn-off responses of AIE-S towards $\mathrm{Cu}^{2+}$. The addition of increasing concentrations of $\mathrm{Cu}^{2+}(0-20 \mu \mathrm{M})$ gradually quenched the fluorescence of AIE-S (20 $\mu M)$. Spectra were taken in HEPES $(10 \mathrm{mM}, \mathrm{pH} 7.4,25 \circ \mathrm{C}, 10 \% \mathrm{THF})$ immediately after the addition of $\mathrm{Cu}^{2+}(\lambda$ ex $350 \mathrm{~nm}$ ). (a) Spectra collected between 490-675 nm. (b) Correlation between the fluorescence intensity at $533 \mathrm{~nm}$ of the system $(\mathrm{y})$ and the molar ratio of $\mathrm{Cu}^{2+}$ to AIE-S (x).

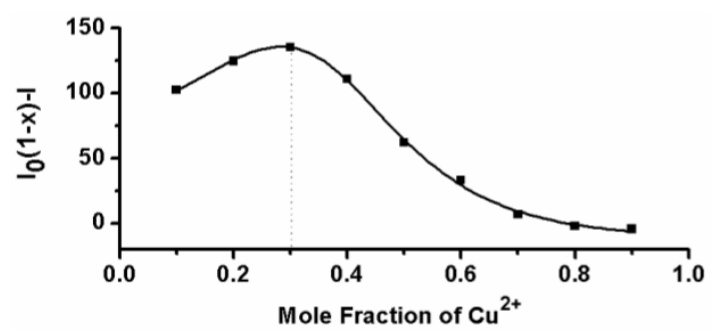

Fig. 3. Job's plot for determining the stoichiometry of AIE-S and $\mathrm{Cu}^{2+}$ in HEPES (I0 $\mathrm{mM}, \mathrm{pH} 7.4,25^{\circ} \mathrm{C}, 10 \%$ THF). The total concentration of AIE-S and $\mathrm{Cu}^{2+}$ was $20 \mu \mathrm{M}$ and the excitation wavelength was $350 \mathrm{~nm}$.

The selectivity of AIE-S to $\mathrm{Cu}^{2+}$ over other cations was then evaluated and it turned out that the fluorescent turn-off response of AIE-S was selective and specific for $\mathrm{Cu}^{2+}$. None of the other cations, including $\mathrm{Ag}^{+}, \mathrm{Al}^{3+}, \mathrm{Ca}^{2+}, \mathrm{Cd}^{2+}, \mathrm{Co}^{2+}, \mathrm{Fe}^{2+}, \mathrm{Fe}^{3+}, \mathrm{Hg}^{2+}, \mathrm{K}^{+}$, $\mathrm{Mg}^{2+}, \mathrm{Mn}^{2+}, \mathrm{Na}^{+}, \mathrm{Ni}^{2+}, \mathrm{Pb}^{2+}$, and $\mathrm{Zn}^{2+}$ was able to generate any obvious quenching effects. Moreover, the fluorescence of AIE-S could still be quenched by $\mathrm{Cu}^{2+}$ in the coexistence of competitive cations mentioned above, indicating that the coordination effect of AIE-S was specific towards $\mathrm{Cu}^{2+}$ (Fig. 4).

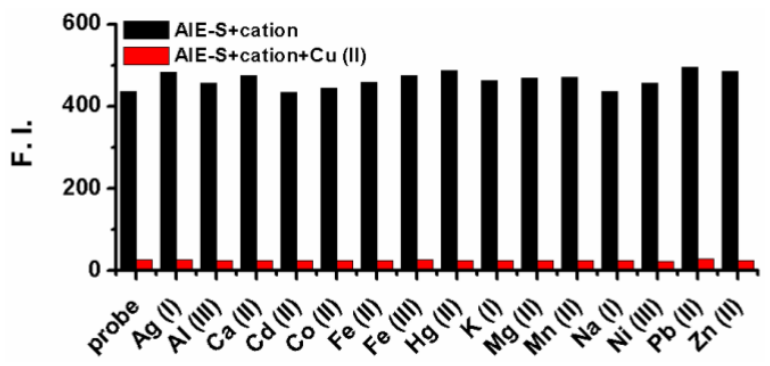

Fig. 4. Fluorescence responses of AIE-S towards various cations with or without the presence of $\mathrm{Cu}^{2+}$. Data were obtained as the fluorescence intensity at $533 \mathrm{~nm}$ ( $\lambda$ ex $350 \mathrm{~nm})$ in HEPES buffer $\left(10 \mathrm{mM}, \mathrm{pH} 7.4,25^{\circ} \mathrm{C}, 10 \% \mathrm{THF}\right)$ right after treating AIE-S with the cation indicated. The concentrations of AIE-S and the cations were both 20 $\mu \mathrm{M}$. For the coexistence experiments, both $\mathrm{Cu}^{2+}$ and the tested substrates were kept at a final concentration of $20 \mu \mathrm{M}$.
To confirm the mechanism shown in Fig. 1, dynamic light scattering measurements were carried out which showed that AIE-S probe has an average diameter of $249.0 \mathrm{~nm}$ in HEPES buffer (10\% THF), while treating the probe with $\mathrm{Cu}^{2+}$ decreased the aggregation with the average diameter reduced to $169.2 \mathrm{~nm}$ (Fig. 5), supporting a plausible mechanism based on copper-initiated de-aggregation.

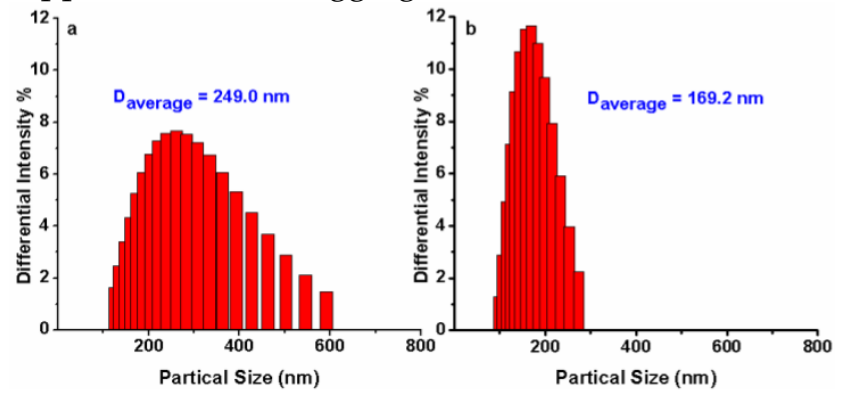

Fig. 5. Size distribution of AIE-S $(20 \mu \mathrm{M})$ before (a) and after (b) the addition of 0.5 eq $\mathrm{Cu}^{2+}$ in HEPES $(10 \mathrm{mM}, \mathrm{pH} 7.4,25 \circ \mathrm{C}, 10 \% \mathrm{THF})$. Data were determined by dynamic light scattering.

Having established AIE-S as a $\mathrm{Cu}^{2+}$ selective complexing ligand, we next study the ability of the AIE-S-Cu system to sense $\mathrm{H}_{2} \mathrm{~S}$. For this purpose, $\mathrm{Na}_{2} \mathrm{~S}$ was employed as an aqueous sulfide source. Much to our delight, the addition of $\mathrm{Na}_{2} \mathrm{~S}$ to the weakly emissive AIE-S-Cu solution triggered an immediate increment in fluorescense intensity, demonstrating the release and aggregation of AIE-S (Fig. 6). The signal response towards $\mathrm{Na}_{2} \mathrm{~S}$ was instant and maximized within seconds since the fluorescent spectrum obtained right after the addition of $\mathrm{Na}_{2} \mathrm{~S}(\mathrm{t}<1 \mathrm{~min})$ was overlapped with that of 30 minutes (Supplementary Material: Fig. S3). Moreover, the logarithm of the fluorescence intensity growth ratio of the system was linear to the concentration of $\mathrm{Na}_{2} \mathrm{~S}$ ranging from 2-15 $\mu \mathrm{M}$ with a correction coefficient of 0.985 (Fig. 6c).

To examine if the fluorescence switch-on property of the AIE-S-Cu complex was specific towards sulfide, its responses towards various common anions and biothiols in HEPES buffer were measured. As shown in Fig. 7, in the presence of various anions, including bio-relevant $\mathrm{F}^{-}, \mathrm{Cl}^{-}, \mathrm{Br}^{-}, \mathrm{I}^{-}, \mathrm{H}_{2} \mathrm{PO}_{4}^{-}, \mathrm{NO}_{3}^{-}$, $\mathrm{CO}_{3}{ }^{2-}, \mathrm{ClO}-$, and sulfur oxyanions such as $\mathrm{SO}_{3}{ }^{2-}, \mathrm{SO}_{4}{ }^{2-}$, $\mathrm{S}_{2} \mathrm{O}_{3}{ }^{2-}$, only $\mathrm{S}^{2-}$ was able to induce a significant fluorescence enhancement. Moreover, common biothiols such as glutathione (GSH) and L- cysteine (L-Cys) which are the major interferents jeopardizing the specificity of reported $\mathrm{H}_{2} \mathrm{~S}$ probes, proved to be innocent in this case (Fig. 7b). What is more, $\mathrm{Na}_{2} \mathrm{~S}$ could still induce a great fluorescence enhancement in the presence of the competitive anions. These results taken together demonstrated the high selectivity of the AIE-S-Cu complex for $\mathrm{H}_{2} \mathrm{~S}$ and its feasibility to detect $\mathrm{H}_{2} \mathrm{~S}$ in the complex biological samples. 

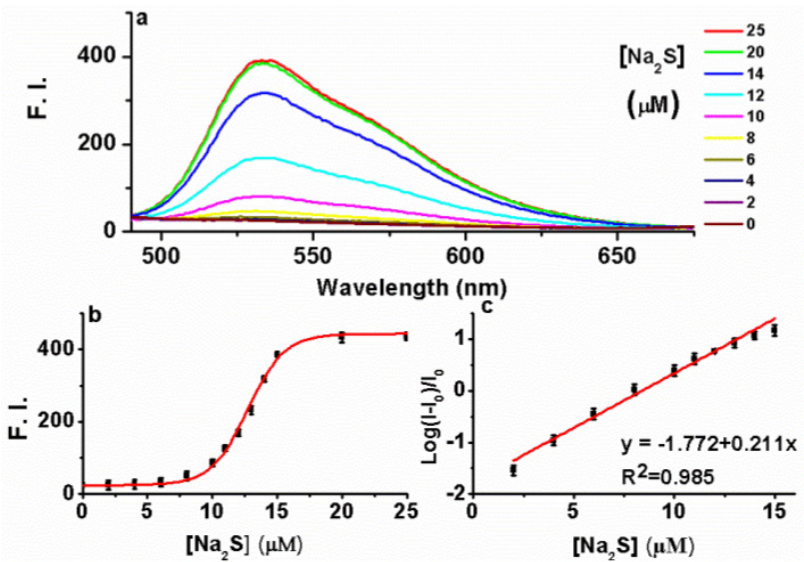

Fig. 6. The fluorescence turn-on responses of AIE-S-Cu towards $\mathrm{Na}_{2} \mathrm{~S}$. (a) Fluorescence spectra of AIE-S-Cu in the presence of various concentrations of $\mathrm{Na}_{2} \mathrm{~S}$. Spectra were taken in HEPES buffer $\left(10 \mathrm{mM}, \mathrm{pH} 7.4,25^{\circ} \mathrm{C}, 10 \% \mathrm{THF}\right)$ instantly after the addition of $\mathrm{Na}_{2} \mathrm{~S}(0-25 \mu \mathrm{M})$. The concentrations of AIE-S and $\mathrm{Cu}^{2+}$ were 20 and I0 $\mu \mathrm{M}$, respectively $(\lambda$ ex $350 \mathrm{~nm}$ ). (b) Plot of fluorescence intensity at $533 \mathrm{~nm}$ vs concentrations of $\mathrm{Na}_{2} \mathrm{~S}$. (c) Regression equation between the logarithm of the fluorescence intensity (mean $\pm S D, n=3$ ) growth ratio at $533 \mathrm{~nm}(\mathrm{y})$ and the corresponding concentration of $\mathrm{Na}_{2} \mathrm{~S}(\mathrm{x})$. $\mathrm{I}_{0}$ was the fluorescence intensity of the quenched AIE-S-Cu.
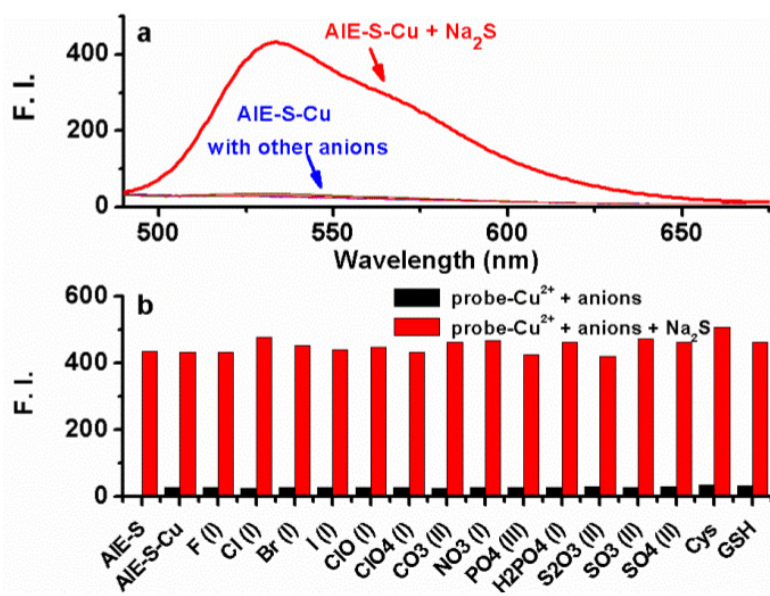

Fig. 7. Fluorescence emission spectra of the AIE-S-Cu (20 $\mu$ M for AIE-S and $10 \mu M$ for $\left.\mathrm{Cu}^{2+}\right)$ in HEPES buffer ( $10 \mathrm{mM}, \mathrm{pH} \mathrm{7.4,25 \circ}$, $10 \%$ THF) right after the addition of $\mathrm{Na}_{2} \mathrm{~S}$ or other biologically relevant anions, biothiols $(20 \mu \mathrm{M})(\lambda \mathrm{ex}=533 \mathrm{~nm})$. (a) Spectra collected between 490-675 nm. (b) Emission intensity at $533 \mathrm{~nm}(\mathrm{y})$ when different species $(x)$ were added.

As a proof of concept we tested the probe in cellular imaging for the detection of sulfide. HeLa cells were incubated with the combination of AIE-S (5 $\mu \mathrm{M})$ and $\mathrm{CuCl}_{2}(3 \mu \mathrm{M})$ for $2 \mathrm{~h}$. The cells were then rapidly washed with PBS and only weak fluorescence was observed under microscopy (Fig. 8a). The cells were then treated with $\mathrm{Na}_{2} \mathrm{~S}(100 \mu \mathrm{M})$ for $15 \mathrm{~min}$ at $37^{\circ} \mathrm{C}$ and resulted in a dramatic increase of intracellular fluorescence (Fig. 8b), which demonstrated the feasibility of AIE-S to image sulfide in live cells.

\section{Conclusions}

We have devised a novel fluorescent probe, AIE-S for the sensitive and rapid detection of $\mathrm{H}_{2} \mathrm{~S}$ in living cells. AIE-S featured with high selectivity, rapid response and aggregation-induced emission characteristics. The preparation of AIE-S is operationally simple and the light-up mechanism is based on $\mathrm{S}^{2-}$ initiated de-coordination and thereafter aggregation of the AIE-S-Cu complex. This probe enables monitoring of $\mathrm{H}_{2} \mathrm{~S}$ in solution and in cells with a high signal-to-noise ratio.

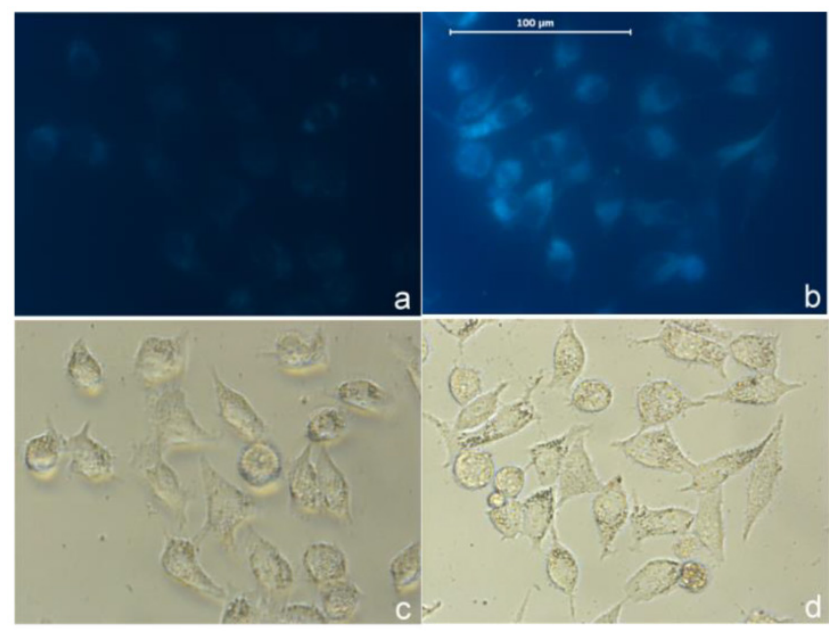

Fig. 8. Imaging $\mathrm{H}_{2} \mathrm{~S}$ in live cells with AIE-S-Cu. Intact HeLa cells were treated with a combination of AIE-S $(5 \mu \mathrm{M})$ and $\mathrm{CuCl}_{2}(3 \mu \mathrm{M})$ for $2 \mathrm{~h}$ and then washed quickly with PBS for imaging (a). The cells were then treated with $\mathrm{Na}_{2} \mathrm{~S}(100 \mu \mathrm{M})$ for 15 min which resulted in a dramatic increase in intracellular fluorescence intensity (b). Images were collected upon excitation using the corresponding filters for DAPI (blue). (c, d): Bright field images of live cells in panel $a$ and $b$.

\section{Supplementary Material}

Scheme S1, Fig.S1 - S3, etc.

http://www.thno.org/v04p1233s1.pdf

\section{Competing Interests}

The authors have declared that no competing interest exists.

\section{References}

1. Abe K, Kimura H. The possible role of hydrogen sulfide as an endogenous neuromodulator. J Neurosci. 1996; 16: 1066-71.

2. Li L, Rose P, Moore PK. Hydrogen sulfide and cell signaling. Annu Rev Pharmacol Toxicol. 2011; 51: 169-187.

3. Kimura H, Shibuya N, Kimura Y. Hydrogen sulfide is a signaling molecule and a cytoprotectant. Antioxid Redox Signal. 2012; 17: 45-57.

4. Stipanuk MH, Beck PW. Characterization of the enzymic capacity for cysteine desulphhydration in liver and kidney of the rat. Biochem J. 1982; 206: 267-77.

5. Kamoun P. Endogenous production of hydrogen sulfide in mammals. Amino Acids. 2004; 26: 243-54.

6. Yang G, Wu L, Jiang B, Yang W, Qi J, Cao K, Meng Q, Mustafa AK, Mu W, Zhang S, Snyder SH, Wang R. $\mathrm{H}_{2} \mathrm{~S}$ as a physiologic vasorelaxant: hypertension in mice with deletion of cystathionine gamma-lyase. Science. 2008; 322: 587-90.

7. Eto K, Asada T, Arima K, Makifuchi T, Kimura H. Brain hydrogen sulfide is severely decreased in Alzheimer's disease. Biochem Biophys Res Commun. 2002; 293: 1485-8.

8. Kamoun P, Belardinelli MC, Chabli A, Lallouchi K, Chadefaux-Vekemans B. Endogenous hydrogen sulfide overproduction in Down syndrome. Am J Med Genet A. 2003; 116A: 310-1.

9. Yang W, Yang G, Jia X, Wu L, Wang R. Activation of $\mathrm{K}_{\text {Atp }}$ channels by $\mathrm{H}_{2} \mathrm{~S}$ in rat insulin-secreting cells and the underlying mechanisms. J Physiol. 2005; 569: 519-31.

10. Li L, Whiteman M, Guan YY, Neo KL, Cheng Y, Lee SW, Zhao Y, Baskar R, Tan $\mathrm{CH}$, Moore PK. Characterization of a novel, water-soluble hydrogen sul- 
fide-releasing molecule (GYY4137): new insights into the biology of hydrogen sulfide. Circulation. 2008; 117: 2351-60.

11. Lee ZW, Zhou J, Chen CS, Zhao Y, Tan CH, Li L, Moore PK, Deng LW. The slow-releasing hydrogen sulfide donor, GYY4137, exhibits novel anti-cancer effects in vitro and in vivo. PLoS One. 2011; 6: e21077.

12. Gong QH, Wang Q, Pan LL, Liu XH, Xin H, Zhu YZ. S-propargyl-cysteine, a novel hydrogen sulfide-modulated agent, attenuates lipopolysaccharide-induced spatial learning and memory impairment: involvement of TNF signaling and NF-KB pathway in rats. Brain Behav Immun. 2011; 25: 110-9.

13. Kashfi K, Olson KR. Biology and therapeutic potential of hydrogen sulfide and hydrogen sulfide-releasing chimeras. Biochem Pharmacol. 2013; 85: 689-703.

14. Wallace JL, Vong L, McKnight W, Dicay M, Martin GR. Endogenous and exogenous hydrogen sulfide promotes resolution of colitis in rats. Gastroenterology. 2009; 137: 569-78.

15. Hannestad U, Margheri S, Sörbo B. A sensitive gas chromatographic method for determination of protein-associated sulfur. Anal Biochem. 1989; 178: 394-8.

16. Qian Y, Karpus J, Kabil O, Zhang SY, Zhu HL, Banerjee R, Zhao J, He C. Selective fluorescent probes for live-cell monitoring of sulphide. Nat Commun. 2011; 2: 495.

17. Liu C, Pan J, Li S, Zhao Y, Wu LY, Berkman CE, Whorton AR, Xian M. Capture and visualization of hydrogen sulfide by a fluorescent probe. Angew Chem Int Ed Engl. 2011; 50: 10327-9.

18. Liu C, Peng B, Li S, Park CM, Whorton AR, Xian M. Reaction based fluorescent probes for hydrogen sulfide. Org Lett. 2012; 14: 2184-7.

19. Lippert AR, New EJ, Chang CJ. Reaction-based fluorescent probes for selective imaging of hydrogen sulfide in living cells. J Am Chem Soc. 2011; 133: 10078-80.

20. Peng H, Cheng Y, Dai C, King AL, Predmore BL, Lefer DJ, Wang B. A fluorescent probe for fast and quantitative detection of hydrogen sulfide in blood. Angew Chem Int Ed Engl. 2011; 50: 9672-5.

21. Yu F, Li P, Song P, Wang B, Zhao J, Han K. An ICT-based strategy to a colorimetric and ratiometric fluorescence probe for hydrogen sulfide in living cells. Chem Commun. 2012; 48: 2852-4.

22. Montoya LA, Pluth MD. Selective turn-on fluorescent probes for imaging hydrogen sulfide in living cells. Chem Commun. 2012; 48: 4767-9.

23. Chen S, Chen ZJ, Ren W, Ai HW. Reaction-based genetically encoded fluorescent hydrogen sulfide sensors. J Am Chem Soc. 2012; 134: 9589-92.

24. Das SK, Lim CS, Yang SY, Han JH, Cho BR. A small molecule two-photon probe for hydrogen sulfide in live tissues. Chem Commun. 2012; 48: 8395-7.

25. Sasakura K, Hanaoka K, Shibuya N, Mikami Y, Kimura Y, Komatsu T, Ueno T, Terai T, Kimura H, Nagano T. Development of a highly selective fluorescence probe for hydrogen sulfide. J Am Chem Soc. 2011; 133: 18003-5.

26. Hou F, Huang L, Xi P, Cheng J, Zhao X, Xie G, Shi Y, Cheng F, Yao X, Bai D, Zeng $\mathrm{Z}$. A retrievable and highly selective fluorescent probe for monitoring sulfide and imaging in living cells. Inorg Chem. 2012; 51: 2454-60.

27. Qu X, Li C, Chen H, Mack J, Guo Z, Shen Z. A red fluorescent turn-on probe for hydrogen sulfide and its application in living cells. Chem Commun. 2013; 49: 7510-2.

28. Hong Y, Lam JW, Tang BZ. Aggregation-induced emission. Chem Soc Rev. 2011; 40: 5361-88.

29. Luo J, Xie Z, Lam JW, Cheng L, Chen H, Qiu C, Kwok HS, Zhan X, Liu Y, Zhu D, Tang BZ. Aggregation-induced emission of 1-methyl-1,2,3,4,5-pentaphenylsilole. Chem Commun. 2001; (18): 1740-1.

30. Hong Y, Lam JW, Tang BZ. Aggregation-induced emission: phenomenon, mechanism and applications. Chem Commun. 2009; (29): 4332-53.

31. Lou X, Hong Y, Chen S, Leung CW, Zhao N, Situ B, Lam JW, Tang BZ. A selective glutathione probe based on AIE fluorogen and its application in enzymatic activity assay. Sci Rep. 2014; 4: 4272.

32. Chen X, Shen XY, Guan E, Liu Y, Qin A, Sun JZ, Tang BZ. A pyridinyl-functionalized tetraphenylethylene fluorogen for specific sensing of trivalent cations. Chem Commun. 2013; 49: 1503-5.

33. Yuan Y, Kwok RT, Feng G, Liang J, Geng J, Tang BZ, Liu B. Rational design of fluorescent light-up probes based on an AIE luminogen for targeted intracellular thiol imaging. Chem Commun. 2014; 50: 295-7.

34. Duan XF, Zeng J, Lü JW, Zhang ZB. Insights into the general and efficient cross McMurry reactions between ketones. J Org Chem. 2006; 71: 9873-6. 